\title{
Operation status and line optimization of Wanda Plaza Parking lot
}

\author{
Zhe Meng ${ }^{1, \mathrm{a}}$, Baohua Guo ${ }^{2, \mathrm{~b}^{*}}$, Huihui Wang ${ }^{3, \mathrm{c}}$, Qingwen Guo ${ }^{4, \mathrm{~d}}$, YeLan Zhu ${ }^{5, \mathrm{e}}$ \\ ${ }^{1,2,3,4,5}$ School of Energy Science and Engineering, Henan Polytechnic University, Jiaozuo, Henan, China
}

\begin{abstract}
Vehicle parking is not only an important problem in urban traffic, but also an important factor affecting the relationship between cities and within cities. In this paper, by investigating the parking conditions of Jiaozuo Wanda Plaza in 2018, important parameters such as average parking time on weekdays and holidays, berth turnover rate, parking utilization rate and centralized parking index were obtained. Based on the obtained parameters, multi-angle optimization analysis was conducted on the parking lot. In order to reduce the congestion of the entrance and exit of parking lots and improve parking efficiency, this paper adopts the method of increasing the entrance and exit of parking lots and optimizing the route. It has great reference value in practical application.
\end{abstract}

\section{INTRODUCTION}

The concept of vehicle parking has been put forward since 1885, when German Carl Benz invented the world's first automobile ${ }^{[1]}$. After the end of the Second World War, the parking of motor vehicles in some big cities abroad has become a serious social problem ${ }^{[2]}$. With the deepening of reform and opening up and the rapid development of national economy, the number of civilian motor vehicle ownership in China has also been growing rapidly ${ }^{[6]}$. Parking Spaces in major cities cannot meet the demand for motor vehicle parking, which becomes more obvious in hospitals ${ }^{[5]}$, railway stations, schools, residential areas and other areas, resulting in traffic congestion and social contradictions ${ }^{[4]}$. Therefore, it is necessary to pay attention to the parking difficulty and parking disorder in order to promote the rapid development of urban social economy ${ }^{[3]}$. This paper takes Jiaozuo Wanda Plaza as an example to show the parking characteristics of the business district, and puts forward some suggestions to improve the existing problems.

\section{OVERVIEW OF THE SQUARE}

\subsection{Overview of Parking Lot Construction}

Jiaozuo Wanda Plaza is located 150 meters southeast of the intersection of Fengshou Road and Minzhu South Road in Jiaozuo Liberated Area. It is surrounded by many residential areas such as Jinxiu Garden, Zhongcheng Garden, Jinxiang Garden and Zijing Garden. It was officially opened on June 30, 2017.The parking lot of Wanda Plaza has parking areas for motor vehicles and non-motor vehicles, in addition to an underground parking garage (which has not been put into use after business, but has been converted into a warehouse), as shown in Figure 1. There are two gates in the parking area of the square, one on Fengshou Road and the other on Minzhu South Road, both of which are left in and right out. The motor vehicle parking lot is divided into three areas: B, C and D. In addition, there are more than a dozen parking spaces for employees. There are 239 parking spaces in area B, 266 parking Spaces in area C, 206 parking Spaces in area $\mathrm{D}$, and a total of 711 parking spaces in area $\mathrm{D}$ for motor vehicles. The parking method is vertical. Two non-motor vehicle parking areas (A and E) are adjacent to Fengshou Road and Minzhu South Road, respectively. The total parking area is 9385.2 square meters.

\footnotetext{
ae-mail: 212002020053@home.hpu.edu.cn

*Corresponding author's e-mail: bguobaohua@139.com

ce-mail: 212002020054@home.hpu.edu.cn

de-mail: 212002020058@home.hpu.edu.cn

ee-mail: 212002020051@home.hpu.edu.cn
} 


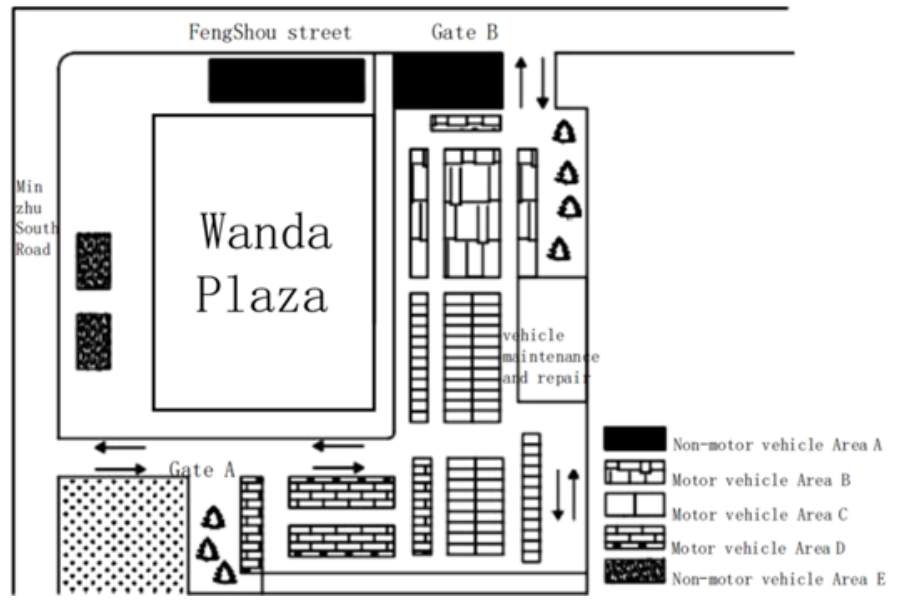

Figure 1 Plan diagram of Wanda Plaza before optimization

\subsection{Motor vehicle parking survey}

The parking survey is conducted manually on working day and rest day. The survey period is from 10:00 to 16:00 on April 18, 2018, and 11:00-18:00 on May 5, 2018.Figure 2 shows the total number of entering, leaving, and parking motor vehicle in the parking lot in each period of working day (April 18) and rest day (May $5)$.

Through the survey, it is found that the number of parking vehicles in each period of working days does not reach the total number of parking spaces in the square, and the number of parking vehicles in each period of rest day is higher than that in working days. After 11:00 am, the number of parkingspaces remains above 467 (working day) and 587 (rest day). On working days and rest days, the peak hours of entering vehicles and leaving vehicles of parking lot are close

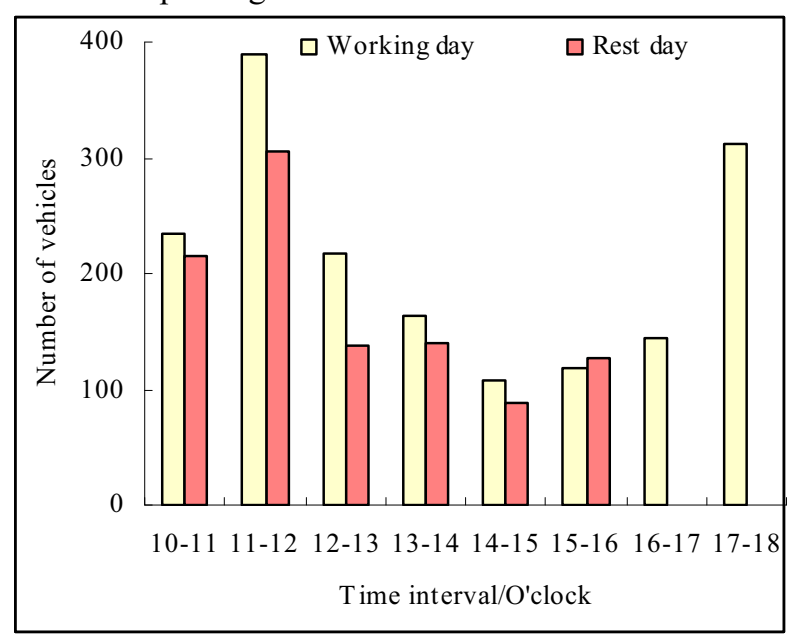

(a) Entering vehicles

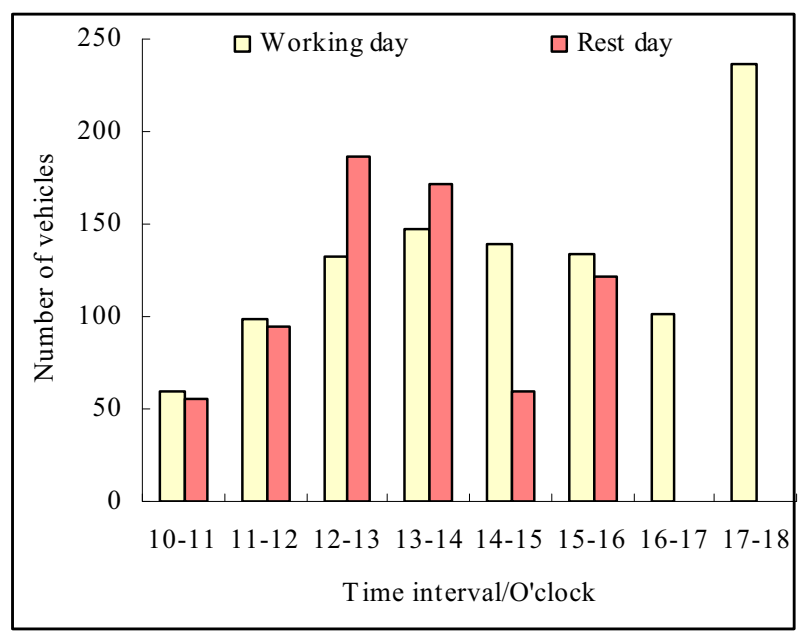

(b) Leaving vehicles

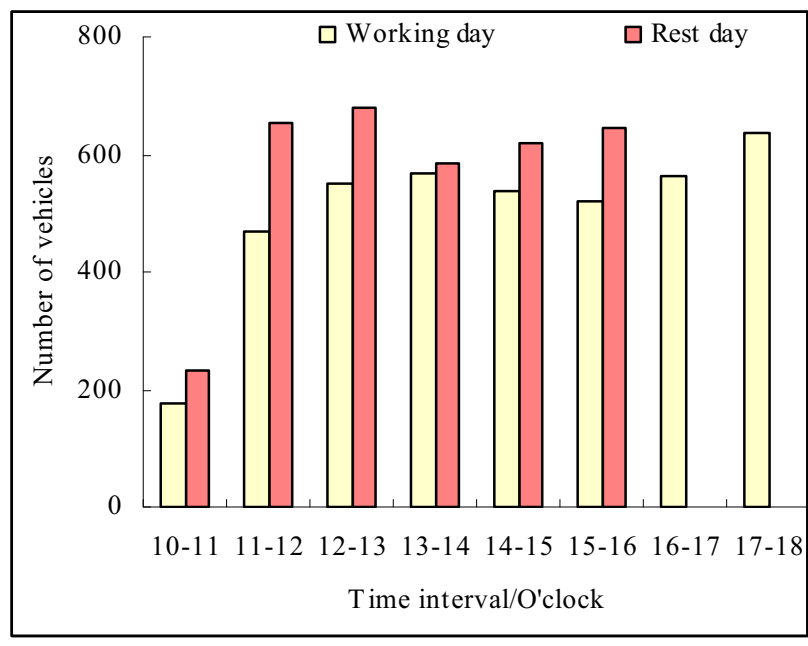

(c) Total parking

Figure 2 Parking survey data

to each other. Among them, the peak hours of entering vehicles are 11:00-12:00 and 17:00-18:00, and the peak hours of leaving vehicles are 12:00-14:00 and 17:00-18:00. In the above rush hours, 389 vehicles entering and 237 vehicles leaving this parking lot, respectively, regularly form traffic congestion at the two 
gates, which has a negative impact on the traffic in the surrounding road network. In addition, according to the parking lot construction regulations, the on-road parking lot with more than 500 parking spaces must have three or more gates. Therefore, a new gate is planned to be added to the parking lot, as shown in Figure 3. At the same time, a traffic light is set up at each gate to facilitate pedestrians to cross the street and protect the safety of passing pedestrians. The traffic police on duty enter the road section to conduct traffic guidance during peak hours.

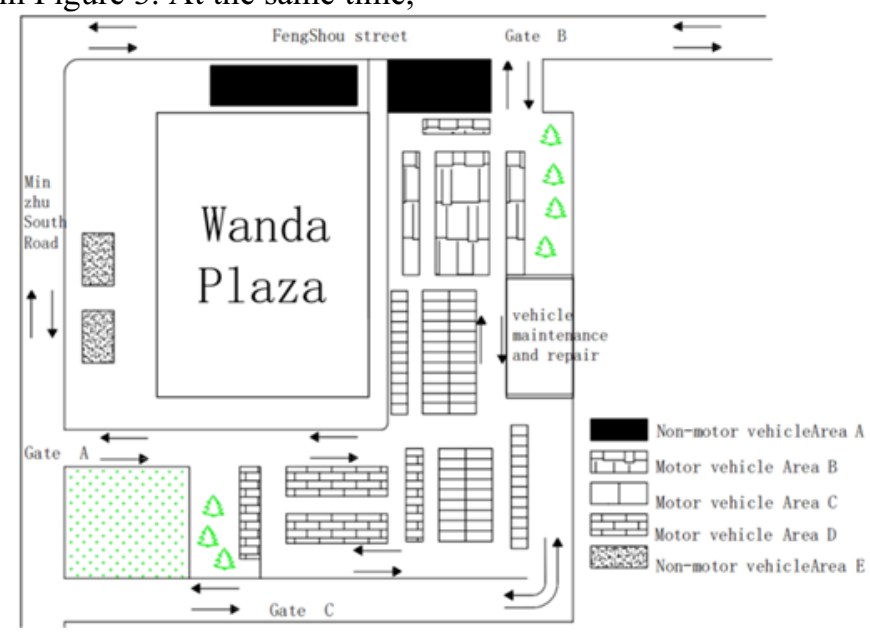

Figure 3 Plan diagram of Wanda Plaza after optimization

\subsection{Parking conditions of motor vehicle parking lots}

Parking duration and parking turnover rate are indicators illustrating the status of parking space usage from different perspectives. The average parking duration is long, and the turnover rate of parking spaces will be low; conversely, the turnover rate of parking spaces will be high. The average parking duration is calculated as follows:

$$
\overline{\mathrm{t}}=\frac{\sum_{\mathrm{i}}^{\mathrm{n}} \mathrm{t}_{\mathrm{i}}}{S}
$$

where $t_{i}$ is the parking duration of the number $i$ car; $S$ stands for actually the number of the parking vehicles;

$$
\overline{\mathrm{t}}=\frac{1889}{1010}=1.87(\mathrm{~h})
$$

Parking capacity refers to the maximum number of parking vehicles within a parking lot that can be legally used. The calculation formula of parking capacity is as follows:

$$
\mathrm{C}=\left[\frac{\sum_{\mathrm{n}}(N \times F)}{E}\right] \times F
$$

where $\mathrm{C}$ stands for the number of parking spaces available; $\mathrm{N}$ is the number of parking spaces available within $\mathrm{T} ; \mathrm{T}$ represents the available parking duration within the observation time; E stands for average parking duration; F represents the adjustment coefficient, which is between 0.85 and 0.95 and increases with the increase of $E$.

$$
\mathrm{C}=\frac{1506}{1.87} \times 0.85=684.4
$$

Parking space turnover rate represents $\delta$ the times that a parking space is reused during a period, which can be used to reflect the utilization degree of parking facilities:

$$
\delta=\frac{S}{C}
$$

where $\mathrm{S}$ represents the actual number of parking vehicles during the survey period; $\mathrm{C}$ stands for the parking capacity;

$$
\delta=\frac{S}{C}=\frac{1010}{684.4}=1.5
$$

The utilization rate of parking lot $U$ during the survey period is calculated by the following formula:

$$
\mathrm{U}=\frac{\sum_{\mathrm{i}=1}^{S}\left(\mathrm{t}_{\mathrm{i}} \times P_{\mathrm{i}}\right)}{T \times C} \times 100 \%
$$

where $t_{i}$ is the parking duration of the number $i$ car; $P_{i}$ represents the number of parking vehicles within the duration of $\mathrm{t}_{\mathrm{i}} ; T$ is the total survey time; $\mathrm{C}$ is the parking capacity of a parking lot;

$$
\mathrm{U}=44.5 \%
$$

The centralized parking index $\mu$ represents the congestion degree of a parking lot at a certain time. The formula of the parking index $\mu$ in peak hours is as follows:

$$
\mu=\frac{N_{\mathrm{j}}}{C}
$$

where $\mathrm{N}_{\mathrm{j}}$ is the number of parking vehicles at time $\mathrm{j}$.

$$
\mu=\frac{N_{\mathrm{j}}}{C}=\frac{469}{684.4}=0.6855
$$


Table 1 Parking space usage status

\begin{tabular}{|c|c|c|}
\hline Index & $\begin{array}{c}\text { Working } \\
\text { day }\end{array}$ & Rest day \\
\hline $\begin{array}{c}\text { Average parking } \\
\text { duration }\end{array}$ & $1.87 \mathrm{~h}$ & $2.13 \mathrm{~h}$ \\
\hline $\begin{array}{c}\text { Parking space turnover } \\
\text { rate }\end{array}$ & 1.5 & 2.768 \\
\hline Utilization rate & $44.5 \%$ & $90.88 \%$ \\
\hline $\begin{array}{c}\text { Centralized parking } \\
\text { index }\end{array}$ & 0.6855 & 1.017 \\
\hline
\end{tabular}

\section{Summary AND Suggestions}

This paper investigates and analyzes the usage of parking lot in Wanda Plaza on woring days and rest days, and finds that the motor vehicle parking lot basically meets the parking demand, but it forms traffic congestion at two existed gates during peak hours, which can be solved by adding a new gate onthe Minzhu south Road. In addition, when the parking demand cannot be met, partial parallel parking spaces can be changed as inclined parking spaces to increase the supply of the parking lot. However, the potential of parking space supply is limited, it is necessary to consider increasing the frequency and route of public transportation that pass through Wanda Plaza, encouraging citizens to use green travel mode and increasing parking facilities for shared bicycles (trams).

\section{ACKNOWLEDGMENTS}

The authors acknowledge the Fundamental Research Funds for the Universities of Henan Province (Grant no. NSFRF180336) and Natural Science Foundation of Henan (Grant no. 202300410183).

\section{REFERENCES}

1. Wang Wei. Traffic Planning [M]. Beijing: People's Communications Press, 2007

2. Wei Liying. Urban Traffic Survey [M]. Beijing: Beijing Jiaotong University Press, 2014

3. Wang Wei, Guo Xiu-cheng. Traffic engineering [M]. Beijing: Southeast University Press, 2000

4. Shao Chunfu. Urban Traffic Planning [M]. Beijing: Beijing Jiaotong University Press, 2014.9

5. Wang Haiyan. Research on Parking in Handan City Central Business District [D]. Hebei: Master thesis of Hebei University of Technology, 2010

6. Ma Liang, Ma Jianxiao, Yan Tao for.Research on Campus Parking Planning and Management [J]. Modern Transportation Technology, 2011.2 